\title{
High dose estrogen treatment increases bone mineral density in male-to-female transsexuals receiving gonadotropin-releasing hormone agonist in the absence of testosterone
}

\author{
Andreas Mueller, Ralf Dittrich, Helge Binder, Werner Kuehnel ${ }^{1}$, Theodoros Maltaris, Inge Hoffmann \\ and Matthias W Beckmann \\ Department of Obstetrics and Gynecology, Erlangen University Hospital, Universitätsstrasse 21-23, D-91054 Erlangen, Germany and ${ }^{1}$ DPC Academy, \\ D-61231 Bad Nauheim, Germany \\ (Correspondence should be addressed to A Mueller; Email: andreas.mueller@gyn.imed.uni-erlangen.de)
}

(A Mueller and R Dittrich contributed equally to this work)

\begin{abstract}
Objective: To study the effect of estrogen (E) on the male skeleton in the absence of testosterone (T). Design: Retrospective analyses of 40 middle-aged transsexuals treated with subcutaneous injections of gonadotropin-releasing hormone agonist every 4 weeks and oral 17-beta-estradiol-valerat $6 \mathrm{mg} /$ day over two years until reassignment surgery.

Methods: The bone mineral density (BMD) in the femoral neck and lumbar spine (L2-L4) was measured with dual-energy X-ray absorptiometry at the beginning of cross-sex hormone treatment, after 12 and 24 months, and serum T, E, sex hormone-binding globulin (SHBG), calcitonin (CAL), osteocalcin (OSC), and urinary free deoxypyridinoline (DPD) were measured.

Results: After 12 months, a significant increase in BMD in the lumbar spine from 1.2 to $1.234 \mathrm{~g} / \mathrm{cm}^{2}$ and after 24 months to $1.274 \mathrm{~g} / \mathrm{cm}^{2}$ was observed. There was a significant increase in BMD in the femoral neck area from 1.068 to $1.109 \mathrm{~g} / \mathrm{cm}^{2}$ after 24 months. There was a significant decrease in serum T levels from 18.65 to $0.57 \mathrm{nmol} / \mathrm{l}$ after 12 months, and to $0.62 \mathrm{nmol} / \mathrm{l}$ after 24 months, a significant increase in SHBG levels from 50.09 to $125 \mathrm{nmol} / \mathrm{l}$ after $12 \mathrm{months}$, and to $130 \mathrm{nmol} / \mathrm{l}$ after 24 months, and a significant increase in serum E levels from 73.42 to $881.6 \mathrm{pmol} / \mathrm{l}$ after $12 \mathrm{months}$, and to $923.62 \mathrm{pmol} / \mathrm{l}$ after 24 months of cross-sex hormone treatment. Serum levels of CAL, OSC and urinary DPD were unchanged.

Conclusion: We conclude that high dose E treatment is able to increase BMD significantly in the femoral neck and lumbar spine independently of serum $\mathrm{T}$ levels in middle-aged men. There is no risk of osteoporosis developing in male-to-female transsexuals receiving GnRHa when there is an adequate E substitution.
\end{abstract}

European Journal of Endocrinology 153 107-113

\section{Introduction}

The relevance of testosterone $(\mathrm{T})$ in comparison with estrogen (E) in regulating bone turnover in men remains unclear, while the maintenance of $\mathrm{E}$ in regulating bone metabolism in women is well established. The traditional belief was that $\mathrm{T}$ is the major sex steroid regulating bone metabolism in men. In elderly men, however, a significant relationship has been found between E serum levels and bone mineral density (BMD) (1-3). In detail, $\mathrm{E}$ was shown to regulate bone resorption enhancing bone mass, while $\mathrm{T}$ together with $\mathrm{E}$ is responsible for bone formation in men (4). Some results, however, suggested that Es play a dominant role in regulating bone turnover in both men and women. Furthermore, in men homozygous mutations in the E receptor-alpha (ER-alpha) gene or homozygous mutations in the aromatase gene have been found to be associated with osteopenia, unfused epiphyses and elevated indices of bone turnover. In men with homozygous mutations in the aromatase gene, E treatment was able to reverse these circumstances successfully (5-8). In addition, in men aged 22-39 years, an increase in BMD correlated more with serum E levels than with $\mathrm{T}$ levels (9). All of this evidence suggests the consideration that $\mathrm{E}$ also plays a role in bone formation processes and in the acquisition of peak bone mass in men. The results of different studies have been contradictory, however. Välimäki et al. reported that E may suppress both bone formation and resorption in a 
population of young Finnish men (10). Several observational studies have attempted to address this issue in elderly men who are affected by age-related loss of $\mathrm{BMD}$, which is a function of both peak bone mass and bone loss with aging $(1,2,11,12)$. In general, studying the effect of $\mathrm{E}$ independently of $\mathrm{T}$ on bone metabolism in younger or middle-aged men is difficult, while suppression of $\mathrm{T}$ is undesired in men in general.

In transsexual people, cross-sex hormone therapy is an important component of medical treatment, especially to provide relief from the dichotomy between body habitus and gender identity (13). Endocrine treatment is guided by the development of the desired mental changes and by the onset and maintenance of an acceptable physical state of the opposite sex. Ideally, this should still be a speedy process. Standards of care for the medical management of transsexual people have been proposed by the Harry Benjamin International Gender Dysphoria Association, Inc. (14). For feminizing endocrine treatment in male-to-female transsexual people, the most widely used drugs are Es in doses two to three times higher than the recommended doses for hormone replacement therapy (HRT) in postmenopausal women. The most widely applied Es are ethinyl estradiol 50-100 $\mu \mathrm{g} /$ day, followed by conjugated equine estrogens $0.625 \mathrm{mg} /$ day or 17-beta-estradiol-valerate $5 \mathrm{mg}$ /day and transdermal or intramuscular estrogens. Oral delivery is preferred by most centers (15). To potentiate the effects of E treatment, hormonal modulators or antiandrogens are used in order to lower serum levels of testosterone or to block its receptor and to limit masculine secondary sexual characteristics. When E treatment alone is less effective in producing adequate feminization, cyproterone acetate $100 \mathrm{mg} /$ day, spironolactone $100-200 \mathrm{mg} /$ day or flutamide $750 \mathrm{mg}$ /day are often used together with Es. A synergistic effect of Es on physical and emotional changes has been observed with these combinations $(15,16)$. With regard to bone metabolism and the risk of developing osteoporosis, only two studies have been published, including 10 and 20 male-to-female transsexuals, respectively, with an observation period of more than one year $(17,18)$. Antiandrogens were used in the reported treatment regimen to reduce $\mathrm{T}$ levels.

We prefer the administration of gonadotropin-releasing hormone agonist (GnRHa), to avoid possible side effects of cyproterone acetate, such as depression and idiosyncratic severe hepatotoxicity, and to reduce serum T levels significantly. GnRHa together with 17beta-estradiol-valerate for endocrine treatment in male-to-female transsexual people is the combination we usually administer until sex reassignment surgery (SRS). In general, GnRHa treatment results in a severe hypogonadal state and is followed by a dramatic decline in endogenous T serum levels. Depletion of T production in combination with $\mathrm{E}$ supplementation results in a radical change in the hormonal environment in biological men. Male-to-female transsexuals are therefore appropriate for studying the role of Es as potential regulators of bone metabolism in men in the absence of $\mathrm{T}$.

In the present study, we evaluated the effects of high dose $\mathrm{E}$ treatment on bone metabolism in middle-aged male-to-female transsexuals with complete androgen deprivation. The aim was to assess whether Es are able to prevent GnRHa-induced bone loss and may be able to increase $\mathrm{BMD}$ in middle-aged men, at which time the peak bone mass has already been achieved (19).

\section{Materials and methods}

\section{Patient population}

The study population comprised 40 healthy middle-aged male-to-female transsexual people; their mean age was 38.4 years (S.D. 11.09) and the median body mass index (BMI) was $24.02 \mathrm{~kg} / \mathrm{m}$ (s.D. 4.00). The diagnosis of transsexualism followed the specifications of the Standards of Care of the Harry Benjamin Gender Dysphoria Association (14). The study was approved by the Ethics Committee of the Department of Medicine at Erlangen University Hospital, and informed consent was obtained from all of the patients. In our hospital, sex reassignment treatment implies 24 months of cross-sex hormone treatment (i.e. GnRHa and 17-betaestradiol-valerate for males) before sex-reassignment surgery with gonadectomy, after which cross-sex hormone treatment has to be continued. All of the patients were interviewed regarding their medical history, which was uneventful. None of the patients were suffering from thrombosis or other vascular diseases. Patients were excluded from the study if they were taking any medications known to affect calcium metabolism (e.g. glucocorticoids, anticonvulsants, calcium or vitamin D supplements, calcitonin (CAL), or bisphosphonates). All of the patients underwent a screening panel, including a complete blood count and serum chemistry profile, and any patients with significant abnormalities in any of these parameters were excluded. Three patients were not included in the study and did not receive oral estrogen treatment because of elevated liver enzymes. Five patients were not included in the study because of prior estrogen treatment due to self medication. At the beginning of the study, all of the patients were eugonadal according to clinical and biochemical criteria. Current exercise, smoking and alcohol consumption were recorded. None of the patients was engaged in excessive exercise activities with a highimpact or high-magnitude bone loading effect (e.g. jumping, sprint running or weight lifting), and none of them had excessive alcohol intake of more than $20 \mathrm{~g}$ /day, or excessive smoking of more than 10 package-years. All of the patients continued with their normal diet throughout the study period. 


\section{Study design}

Retrospective analysis of the study population treated over 24 months with subcutaneous injections of $3.8 \mathrm{mg}$ goserelin acetate (Zoladex GYN; Astra Zeneca, Wedel, Germany) every 4 weeks in combination with $6 \mathrm{mg}$ 17-beta-estradiol-valerate per day (Progynova 21; Schering, Berlin, Germany) until sex-reassignment surgery. Bone mineral density was measured and blood was sampled in the morning before $1000 \mathrm{~h}$ to assess serum T, E, and SHBG levels at the beginning of cross-sex hormone treatment, after 12 and 24 months. All blood samples were assayed for hormone parameters immediately in our routine laboratory. In addition, CAL and osteocalcin (OSC) were measured at the beginning of cross-sex hormone treatment, after 12 and 24 months. On the same day, the first morning urine was collected to measure DPD.

\section{Bone mass measurements}

BMD of the lumbar spine at the level of $\mathrm{L} 2-\mathrm{L} 4$ and the femoral neck was measured by dual-energy x-ray absorptiometry using a Prodigy densitometer with encore software platform (General Electric Medical Systems, Solingen, Germany). Short-term in vivo reproducibility was $1.04 \%$ in the lumbar spine (L2-L4) and $1.7 \%$ in the femoral neck, and long-term reproducibility (i.e. the coefficient of variation about the slope of repeated measurements within subjects over 3 years) between 1.9\% (lumbar spine (L2-L4)) and 1.8\% (femoral neck). BMD is expressed in $\mathrm{g} / \mathrm{cm}^{2}$ and in age- and race-adjusted values (z-scores) according to the manufactures normative database. Z-scores of 0 to -1.5 are considered normal, from -1.5 to -2.5 as osteopenic, and below -2.5 as osteoporotic.

\section{Biochemical measurements}

All assays were performed in our routine diagnostic endocrinology laboratory using established commercial assays routinely monitored by participation in external quality-control programs. Serum parameters (T, E, SHBG, CAL, OSC and DPD) were measured with chemiluminescent enzyme immunoassays (Immulite 2000, Diagnostic Products Corp., Los Angeles, USA). The calibration range of the T assay was $0.7-55 \mathrm{nmol} / \mathrm{l}$, with an analytical sensitivity of $0.5 \mathrm{nmol} / \mathrm{l}$. The cross-reaction with 5alpha-dihydrotestosterone was $2 \%$. The calibration range of the E assay was $73-7342 \mathrm{pmol} / \mathrm{l}$, with an analytical sensitivity of $55 \mathrm{pmol} / \mathrm{l}$. The crossreactivity with 17 -beta-estradiol-valerate was $1.14 \%$. The calibration range of the SHBG assay was up to $180 \mathrm{nmol} / \mathrm{l}$, with an analytical sensitivity of $0.02 \mathrm{nmol} / \mathrm{l}$. No cross-reactivity with other compounds was known. CAL was measured in fasting morning serum samples. After complete clot formation, serum was separated from cells by low-speed centrifugation.
The serum was frozen immediately. The calibration range of the assay was up to $2000 \mathrm{pg} / \mathrm{ml}$, with an analytical sensitivity of $2 \mathrm{pg} / \mathrm{ml}$. No cross-reactivity with other compounds was known. OSC was measured in plasma samples. Blood was collected by venipuncture into iced heparinized tubes. After separation of plasma from cells in a refrigerated centrifuge, aliquots were frozen immediately in plastic tubes. The calibration range of the assay was up to $100 \mathrm{pg} / \mathrm{ml}$, with an analytical sensitivity of $0.1 \mathrm{ng} / \mathrm{ml}$. No cross-reactivity with other compounds was known. DPD was measured in first morning urine before $1000 \mathrm{~h}$. Urine samples were stored frozen at $-20{ }^{\circ} \mathrm{C}$. The calibration range of the assay was 7-300 nM, with an analytical sensitivity of $6 \mathrm{nM}$. No cross-reactivity with other compounds, e.g. pyridinoline, was known. To correct for variations in urinary flow, the DPD results were normalized to the urinary creatinine concentration and expressed as nanomoles DPD per liter divided by millimoles creatinine per liter (nM DPD/mM creatinine). Serum and urine samples were stored at $-70^{\circ} \mathrm{C}$ until assayed.

\section{Statistics}

The primary study end point was to show a change in BMD in the femoral neck or lumbar spine due to E treatment in the absence of normal T serum levels in cross-sex hormone-treated transsexuals receiving GnRHa. Changes in the BMD, T, E, SHBG, CAL, OSC and DPD levels after 12 months and 24 months of intervention were compared with baseline levels using paired $t$ tests. The population $(n=40)$ was strictly treated and the parameters were analyzed according to the protocol (ATP). Statistical analyses were carried out using the SAS program, version 8.1 (SAS Institute, Inc., Cary, NC, USA). Values are expressed as means and S.D. $P$ values less than 0.05 were considered statistically significant.

\section{Results}

The baseline characteristics of the complete study population are shown in Table 1. The BMI remained unchanged during the intervention period; the initial BMI was 24.02 (S.D. 4.00) compared with 23.99 (s.D. 3.98 ) after 12 months and $24.25 \mathrm{~kg} / \mathrm{m}$ (S.D. 3.09) after 24 months.

\section{Hormone values}

After initiating cross-sex hormone treatment, the patients' hypogonadal status was regularly checked by measuring gonadotropins every 12 weeks. Adequate suppression of gonadotropins was observed during whole study period (data not shown). There was a significant decrease in serum $\mathrm{T}$ levels from 18.65 (S.D. 6.41) to 0.57 (S.D. 0.308; $P<0.001$ ) after 12 months, and to $0.62 \mathrm{nmol} / \mathrm{l}$ (S.D. $0.499 ; P<0.001$ ) 
Table 1 Baseline characteristics of the study population $(n=40)$.

\begin{tabular}{lcc}
\hline Age $(\mathrm{yrs})$ & $38.39(11.09)$ & $18-62$ \\
$\mathrm{BMI}\left(\mathrm{kg} / \mathrm{m}^{2}\right)$ & $24.02(4.00)$ & $18.82-35.51$ \\
Serum T $(\mathrm{nmol} / \mathrm{l})$ & $18.65(6.41)$ & $8.00-32.60$ \\
Serum E (pmol/l) & $73.16(16.73)$ & $51.39-172.54$ \\
Serum SHBG $(\mathrm{nmol} / \mathrm{l})$ & $50.09(47.50)$ & $21.00-203.05$ \\
Femoral neck BMD $\left(\mathrm{g} / \mathrm{cm}^{2}\right)$ & $1.07(0.14)$ & $0.83-1.33$ \\
Z-score & $0.15(1.02)$ & $-1.30-2.30$ \\
Lumbar spine BMD $\left(\mathrm{g} / \mathrm{cm}^{2}\right)$ & $1.20(0.12)$ & $1.05-1.60$ \\
Z-score & $0.20(1.32)$ & $-1.20-3.20$ \\
\hline
\end{tabular}

All values are expressed as means (S.D.) and ranges. BMI, body mass index; BMD, bone mineral density; E, estrogen; SHBG, sex hormone-binding globulin; $\mathrm{T}$, testosterone.

after 24 months. SHBG levels significantly increased from 50.09 (S.D. 47.5) to 125 (S.D. 60.4; $P<0.001$ ) after 12 months, and to $130.05 \mathrm{nmol} / \mathrm{l}$ (S.D. 43.6; $P<0.001)$ after 24 months. There was also a significant increase of serum E levels from 73.42 (S.D. 55) to 881.6 (S.D. 788.5 ; $P<0.001$ ) after 12 months, and to $923.62 \mathrm{pmol} / \mathrm{l}$ (S.D. 489.66; $P<0.001$ ) after 24 months of cross-sex hormone treatment (Table 2).

\section{Bone mineral density}

Changes in femoral neck BMD and lumbar spine BMD (L2-L4) after 12 months and after 24 months of cross-sex hormone treatment are shown in Fig. 1. In general, an increase in BMD was observed in both the femoral neck and the lumbar spine. The change in the femoral neck BMD after 12 months of treatment, from 1.068 (S.D. 0.142 ) to $1.08 \mathrm{~g} / \mathrm{cm}^{2}$ (S.D. 0.138 ) was not considered significant $(P=0.23)$. However, there was a significant increase $(P=0.010)$ in the femoral neck BMD from 1.068 (S.D. 0.142) to $1.109 \mathrm{~g} / \mathrm{cm}^{2}$ (S.D. 0.116 ) after 24 months, while a significant increase in the lumbar spine BMD from 1.200 (S.D. 0.125) to 1.234 (S.D. 0.140) after 12 months $(P=0.034)$, and to $1.274 \mathrm{~g} / \mathrm{cm}^{2}$ (S.D. 0.112$)$ after 24 months $(P=0.0001)$ was observed. The changes in the BMD in the lumbar spine after 24 months compared with the BMD after 12 months were also significant $(P=0.0003)$. Z-scores of the femoral neck BMD increased from 0.15 (S.D. 1.02) to 0.20 (S.D. 1.05) after 12 months and to 0.45 (S.D. 0.92) after 24 months. Z-scores of the lumbar spine BMD increased from 0.20 (S.D. 1.32) to 0.25 (S.D. 1.03) after 12 months and to 0.42 (S.D. 0.97) after 24 months.

\section{Bone turnover markers}

Data for the bone turnover markers at the beginning of cross-sex hormone treatment, after 12 and 24 months of the intervention period are shown in Table 3. Serum CAL levels of $6.07,5.95$ and $6.32 \mathrm{pg} / \mathrm{ml}$ were near the lower reference level, which ranges from 3 to $19 \mathrm{pg} / \mathrm{ml}$ in healthy men. OSC values of 11.01, 9.69 and $10.17 \mathrm{ng} / \mathrm{ml}$ were also within the normal range of 3.1 to $13.7 \mathrm{ng} / \mathrm{ml}$. The reference range of deoxypyridinoline (DPD) in healthy men has been established as 2.3-5.4 nM DPD/mM creatinine. DPD values of 4.27 at the beginning of cross-sex hormone treatment were decreased, although not significantly, to 3.8 after 12 months and were $4.17 \mathrm{nM} \mathrm{DPD} / \mathrm{mM}$ creatinine after 24 months.

\section{Discussion}

This study demonstrated that high dose E treatment for 24 months is able to increase the BMD in the femoral neck and lumbar spine significantly in men receiving GnRHa for male-to-female cross-sex hormone treatment. Bone resorption was not affected in our study population reflected by unchanged DPD values.

The dosages used were two to three times higher than the recommended doses for hormone replacement therapy (HRT) in postmenopausal women, in whom the physiological decrease in E levels after the menopause is well known to be associated with decreased BMD and an increased risk of osteoporotic fractures. In postmenopausal women there is wide interindividual variability in serum E levels during $\mathrm{E}$ treatment for HRT (20). In our study group measured E levels were in the estimated range, accordingly two to three times higher in comparison with women receiving the recommended doses of HRT with $2 \mathrm{mg}$ /day of 17-betaestradiol-valerate $(20,21)$.

In different studies $\mathrm{E}$ levels were found to correlate better with BMD than T levels $(1,2,11,12,22,23)$. However, traditional belief has been that $\mathrm{T}$ is the dominant sex steroid regulating bone metabolism in men, whereas previous epidemiological studies have found no association or even a negative association between serum $\mathrm{T}$ levels and BMD or vertebral fractures in aging men. Klein et al. (24) and Lorentzon et al. (25) reported data from very young boys without

Table 2 Baseline values of serum testosterone (T), estrogen (E), and sex hormone-binding globulin (SHBG) levels in 40 male-tofemale transsexuals after 12 months and after 24 months of cross-sex hormone treatment. Data are expressed means (S.D.).

\begin{tabular}{lcccr}
\hline & Baseline $(n=40)$ & 12 months $(n=40)$ & 24 months $(n=40)$ & $P$-value \\
\hline Serum T (nmol/l) & $18.65(6.41)$ & $0.57(0.31)$ & $0.62(0.50)$ & $<0.001$ \\
Serum E (pmol/l) & $73.40(55.01)$ & $881.51(788.51)$ & $923.60(489.71)$ & $<0.001$ \\
Serum SHBG (nmol/l) & $50.09(47.50)$ & $125.00(60.40)$ & $130.05(43.61)$ & $<0.001$ \\
\hline
\end{tabular}

E, normal ranges < $206 \mathrm{pmol} / \mathrm{l}$; SHBG, $13-71 \mathrm{nmol} / \mathrm{l} ; \mathrm{T}, 8.49-55.47 \mathrm{nmol} / \mathrm{l}$. Inter- and intra-assay CV's were always below $11 \%$ at mid-range concentrations. 


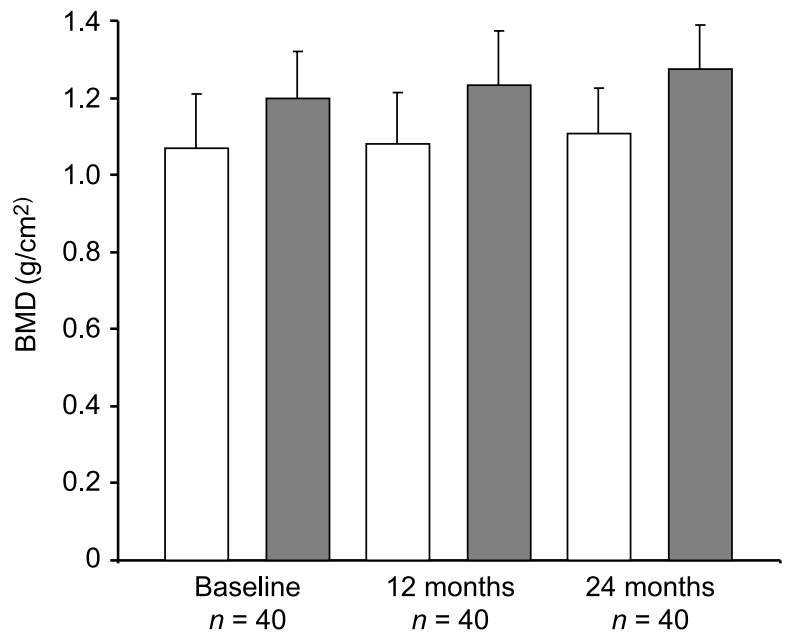

Figure 1 Effect of cross-sex hormone treatment on femoral neck bone mineral density (BMD; open bars) and lumbar spine BMD (grey bars) after 12 months and 24 months (data are expressed as means \pm S.D.). Changes in BMD after 12 months compared to baseline levels were considered significant for the lumbar spine at $P=0.034$, after 24 months for the femoral neck at $P=0.010$ and for the lumbar spine at $P=0.0001$. Changes in BMD after 24 months compared to levels after 12 months were significant for the lumbar spine at $P=0.00035$.

suppression of $\mathrm{T}$, in whom they found no correlation between $\mathrm{E}$ levels and $\mathrm{BMD}$ by single point measurements. In the elderly, bioavailable $\mathrm{E}$ as well as $\mathrm{T}$ levels decline significantly and are associated with age-related bone loss as a result of E deficiency in aging men (11). Studying the effect of estradiol in aging men is of great interest, as the plasma concentrations of estradiol and its production rate are significantly higher in elderly men than in postmenopausal women (26).

The roles of $\mathrm{E}$ and $\mathrm{T}$ in relation to bone metabolism in men still remain enigmatic, and studying the effects of $\mathrm{E}$ in the absence of $\mathrm{T}$, which is the predominant sex steroid in men, is difficult to achieve. E treatment or the elimination of endogenous T production in men is not generally acceptable due to the undesirable side effects, except in men with prostate cancer, for example. However, prostate cancer is a problem in the elderly. In male-tofemale transsexual people, eliminating endogenous $\mathrm{T}$ production is accepted and is an essential part of the feminizing endocrine treatment at any age. This group of patients is therefore an appropriate 'model' for studying the effects of Es in men. Concerning bone metabolism and BMD values, there are only some reports in male-to-female transsexuals receiving combinations of ethinyl estradiol and cyproterone acetate. In 10 patients, Schlatterer et al. reported a low risk of developing osteoporosis (17). In 20 male-to-female transsexuals, van Kesteren et al. demonstrated an increase in lumbar spine BMD after 1 year and a decrease again after $28-$ 63 months of cross-sex hormone treatment using cyproterone acetate $100 \mathrm{mg} /$ day in combination with ethinyl estradiol $100 \mu \mathrm{g} /$ day until SRS after 12-18 months. Bone turnover markers (alkaline phosphatase, OSC, urinary calcium and hydroxyproline excretion) were significantly lower after 1 year of hormone treatment, demonstrating a decrease in bone turnover (18). There was no severe loss of lumbar BMD as long as gonadotropin levels were suppressed by adequate E substitution. In the population described by van Kesteren et al. (18), T levels after 1 year and after 28-63 months were also two-fold higher in comparison with $\mathrm{T}$ levels in the present study group. In a population of 56 male-to-female transsexuals, the results were similar after an observation period of 1 year, also reported by van Kesteren et al. (27).

Compared with $\mathrm{T}$ levels found in our study group, this clearly demonstrates that suppression of $\mathrm{T}$ production is more effective using GnRHa than using the combination of ethinyl estradiol and cyproterone acetate.

But GnRHa treatment or orchidectomy in men is followed by osteoporosis and an increased risk of fractures (28-38). Hypogonadal or orchidectomized men with extremely low levels of $\mathrm{E}$ and $\mathrm{T}$ who tend to develop rapid bone loss should therefore be considered for e.g. bisphosphonate therapy (28). Smith et al. (39) demonstrated that raloxifene increases BMD in severely hypogonadal men receiving GnRHa for prostate cancer. DPD levels as a marker for bone turnover, especially for increased bone resorption, also decreased in men treated with raloxifene (39). In particular, DPD showed a better analytical performance with regard to bone resorption, with the least biological variability (40). Bone turnover markers were unchanged in this study population, with low levels of CAL, normal OSC levels and no significantly different DPD levels after 12 and 24 months of intervention.

In the present study, we found an increase in BMD in biological men with very low serum $\mathrm{T}$ levels due to

Table 3 Bone turnover markers after 12 months and 24 months of cross-sex hormone treatment. Data are expressed as means (S.D.).

\begin{tabular}{lccrc}
\hline & Baseline $(n=40)$ & 12 months $(n=40)$ & 24 months $(n=40)$ & $P$-value \\
\hline Calcitonin (pg/ml) & $6.07(3.98)$ & $5.95(4.28)$ & $6.32(5.14)$ & n.s. \\
Osteocalcin (ng/ml) & $11.01(4.21)$ & $9.69(4.36)$ & $10.17(4.78)$ & n.s. \\
Deoxypyridinoline (DPD) (nM DPD/nM creatinine) & $4.27(1.15)$ & $3.80(1.17)$ & $4.17(1.17)$ & n.s. \\
\hline
\end{tabular}

n.s., not significant; calcitonin, normal ranges $<18.20 \mathrm{pg} / \mathrm{ml}$; Osteocalcin, $3.10-13.70 \mathrm{ng} / \mathrm{ml}$; DPD, 2.30-5.40 nM DPD/nM creatinine. Inter- and intraassay CV's were always below $11 \%$ at mid-range concentrations. 
GnRHa application in the presence of concomitant high dose E treatment.

Bone resorption remained unchanged in our study population, but increased BMD may be due to either stimulated bone formation or increased bone mineralization. It also remains unclear, whether the BMD increasing effect is due to the high dosage of Es or due to the kind of E. In contrast, van Kesteren et al. used ethinyl estradiol $100 \mu \mathrm{g} /$ day in their study populations and the dosage was reduced to $50 \mu \mathrm{g} /$ day after SRS (18, 27). Different studies have described no effect on BMD of the administration of ethinyl estradiol for contraception or in young women suffering from amenorrhea, while bone turnover markers were decreased (41-45). In postmenopausal women, ethinyl estradiol plus calcium administration for 2 years increased BMD in the lumbar spine, as reported by Speroff et al. in 1996 (46). Doren et al. (47) reviewed the effect of specific postmenopausal hormone therapies on bone mineral density in women published between 1990 and December 2002. The impact on BMD did not appear to differ between any E groups.

We used 17-beta-estradiol-valerate in our E treatment regimen, which is more effective in generating a greater hormonal reservoir of estrogenic metabolites - for example, estrone, estrone sulfate, estradiol, and estradiol sulphate - and their metabolism is equivalent to that of natural 17-beta-estradiol (21). Also taking into account that this study, due to its very special patient group, has some limitations relating to the study design (e.g. missing control group, retrospective analysis per protocol), it may be speculated, that the use of 17-beta-estradiol together with the higher $\mathrm{E}$ dosages might be the cause for the BMD increasing effect in the study group.

In summary, E treatment using 17-beta-estradiolvalerate at dosages of $6 \mathrm{mg} /$ day increased BMD significantly in the femoral neck and lumbar spine in men receiving GnRHa, who are at increased risk of developing osteoporosis. There is no risk of developing osteoporosis in male-to-female transsexuals receiving GnRHa when there is an adequate E substitution.

\section{References}

1 Greendale GA, Edelstein S \& Barret-Conner E. Endogenous sex steroids and bone mineral density in older women and men: the Rancho Bernardo Study. Journal of Bone and Mineral Research 199712 1833-1843.

2 Center JR, Nguyen TV, Sambrook PN \& Eisman JA. Hormonal and biochemical parameters in the determination of osteoporosis in elderly men. Journal of Clinical Endocrinology and Metabolism $1999843626-3635$.

3 Amin S, Zhang Y, Sawin CT, Evans SR, Hannan MT, Kiel DP, Wilson PW \& Felson DT. Association of hypogonadism and estradiol levels with bone mineral density in elderly men from the Framingham Study. Annals of Internal Medicine 2000 $133951-963$.

4 Falahati-Nini A, Riggs BL, Atkinson EJ, O'Fallon WM, Eastell R \& Khosla S. Relative contributions of testosterone and estrogen in regulating bone resorption and formation in normal elderly men. Journal of Clinical Investigation 2000106 1553-1560.

5 Smith EP, Boyd J, Frank GR, Takahashi H, Cohen RM, Specker B, Williams TC, Lubhan DB \& Korach KS. Estrogen resistance caused by a mutation in the estrogen-receptor gene in a man. New England Journal of Medicine 1994331 1056-1061.

6 Morishima A, Grumbach MM, Simpson ER, Fisher C \& Qin K. Aromatase deficiency in male and female siblings caused by a novel mutation and the physiological role of estrogens. Journal of Clinical Endocrinology and Metabolism 199580 3689-3698.

7 Carani C, Qin K, Simoni M, Faustini-Fustini M, Serpente S, Boyd J, Korach KS \& Simpson ER. Effect of testosterone and estradiol in a man with aromatase deficiency. New England Journal of Medicine $199733791-95$.

8 Bilezikan JP, Morishima A, Bell J \& Brumbach MM. Increased bone mass as a result of estrogen therapy in a man with aromatase deficiency. New England Journal of Medicine 1998339 599-603.

9 Khosla S, Melton III J, Atkinson EJ \& O'Fallon WM. Relationship of serum sex steroid levels to longitudinal changes in bone density in young versus elderly men. Journal of Clinical Endocrinology and Metabolism 200186 3555-3561.

10 Välimäki V, Alfthan H, Ivaska K, Pettersson LK, Stenman UH \& Välimäki M. Serum estradiol, testosterone, and sex hormone-binding globulin as regulators of peak bone mass and bone turnover rate in young Finnish men. Journal of Clinical Endocrinology and Metabolism 200489 3785-3789.

11 Khosla S, Melton LJ III, Atkinson EJ, O’Fallon WM, Klee GG \& Riggs BL. Relationship of serum sex steroid levels and bone turnover markers with bone mineral density in men and women: a key role for bioavailable estrogen. Journal of Clinical Endocrinology and Metabolism 199883 2266-2274.

12 Slemenda CW, Longcope C, Zhou L, Hui SL, Peacock M \& Johnston CC. Sex steroids and bone mass in older man: positive associations with serum estrogens and negative associations with androgens. Journal of Clinical Investigation $1997 \mathbf{1 0 0}$ 1755-1759.

13 Hamburger C. Endocrine treatment of male and female transsexualism. In Transsexualism and sex reassignment, pp 291-307. Eds R Green \& J Money. Baltimore: John Hopkins Press, 1969.

14 The Harry Benjamin International Gender Dysphoria Association standards of care for gender identity disorders, 6th version 2001. http://www.hbigda.org/soc.html. Retrieved 2002, November 17.

15 Moore E, Wisniewski A \& Dobs A. Endocrine treatment of transsexual people: a review of treatment regimens, outcomes, and adverse effects. Journal of Clinical Endocrinology and Metabolism 200388 3467-3473.

16 Levy A, Crown A \& Reid R. Endocrine intervention for transsexuals. Clinical Endocrinology 200359 409-418.

17 Schlatterer K, Auer DP, Yassouridis A, von Werder K \& Stalla GK. Transsexualism and osteoporosis. Experimental and Clinical Endocrinology and Diabetes 1998106 365-368.

18 van Kesteren P, Lips P, Gooren LJ, Asscheman H \& Megens J. Longterm follow-up of bone mineral density and bone metabolism in transsexuals treated with cross-sex hormones. Clinical Endocrinology 199848 347-354.

19 Bonjour JP, Theintz G, Buchs B, Slosman D \& Rizzoli R. Critical years and stages of puberty for spinal and femoral bone mass accumulation during adolescence. Journal of Clinical Endocrinology and Metabolism 199173 555-563.

20 Kuhl H. Pharmacology of estradiol and estriol. Menopause Review $2000523-44$.

21 Aedo AR, Landgren BM \& Diczfalusy E. Pharmacokinetics and biotransformation of orally administered oestrone sulphate and oestradiol valerate in postmenopausal women. Maturitas 1990 $12333-343$.

22 Goderie-Plomp HW, van der Klift M, de Ronde W, Hofman A, de Jong FH \& Pols HA. Endogenous sex hormones, sex hormonebinding globulin, and the risk of incident vertebral fractures in elderly men and women: the Rotterdam Study. Journal of Clinical Endocrinology and Metabolism $2004893261-3269$. 
23 Ongphiphadhanakul B, Rajatanavin R, Chanprasertyothin S, Piaseu N \& Chailurkit L. Serum oestradiol and oestrogen-receptor gene polymorphism are associated with bone mineral density independently of serum testosterone in normal males. Clinical Endocrinology $1998 \mathbf{4 9} 803-809$.

24 Klein KO, Larmore KA, de Lancey E, Brown JM, Considine RV \& Hassink SG. Effect of obesity on estradiol level, and its relationship to leptin, bone maturation, and bone mineral density in children. Journal of Clinical Endocrinology and Metabolism $1998 \mathbf{8 3}$ 3469-3475.

25 Lorentzon M, Lorentzon R, Backstrom T \& Nordstrom P. Estrogen receptor gene polymorphism, but not estradiol levels, is related to bone density in healthy adolescent boys: a cross-sectional and longitudinal study. Journal of Clinical Endocrinology and Metabolism $1999844597-4601$.

26 Vermeulen A, Kaufman JM, Goemaere S \& van Pottelberg I. Estradiol in elderly men. Aging Male 20025 98-102.

27 van Kesteren P, Lips P, Deville W, Popp-Snijders C, Asscheman H, Megens J \& Gooren L. The effect of one-year cross-sex hormonal treatment on bone metabolism and serum insulin-like growth factor-1 in transsexuals. Journal of Clinical Endocrinology and Metabolism $1996812227-2232$.

28 Smith MR. Management of treatment-related osteoporosis in men with prostate cancer. Cancer Treatment Reviews 200329 211-218.

29 Smith MR, McGovern FJ, Zietman AL, Fallon MA, Hayden DL, Schoenfeld DA, Kantoff PW \& Finkelstein JS. Pamidronate to prevent bone loss during androgen-deprivation therapy for prostate cancer. New England Journal of Medicine 2001345948 -955.

30 Maillefert JF, Sibilia J, Michel F, Saussine C, Javier RM \& Tavernier C. Bone mineral density in men treated with synthetic gonadotropin-releasing hormone agonists for prostatic carcinoma. Journal of Urology $1999 \mathbf{1 6 1} 1219-1222$.

31 Diamond T, Campbell J, Bryant C \& Lynch W. The effect of combined androgen blockade on bone turnover and bone mineral densities in men treated for prostate carcinoma: longitudinal evaluation and response to intermittent cyclic etidronate therapy. Cancer $1998831561-1566$.

32 Townsend MF, Sanders WH, Northway RO \& Graham SD Jr. Bone fractures associated with luteinizing hormone-releasing hormone agonists used in the treatment of prostate carcinoma. Cancer $199779545-550$.

33 Hatano T, Oishi Y, Furuta A, Iwamuro S \& Tashiro K. Incidence of bone fracture in patients receiving luteinizing hormone-releasing hormone agonists for prostate cancer. BJU International $2000 \mathbf{8 6}$ 449-452.

34 Oefelein MG, Ricchuiti V, Conrad W, Seftel A, Bodner D, Goldman H \& Resnick M. Skeletal fracture associated with androgen suppression induced osteoporosis: the clinical incidence and risk factors for patients with prostate cancer. Journal of Urology $20011661724-1728$.

35 Smith MR. The role of bisphosphonates in men with prostate cancer receiving androgen deprivation therapy. Oncology 2003 18 (Suppl 3) 21-25.

36 Doran PM, Riggs BL, Atkinson EJ \& Khosla S. Effects of raloxifene, a selective estrogen receptor modulator, on bone turnover markers and serum sex steroid and lipid levels in elderly men. Journal of Bone and Mineral Research 200116 2118-2125.

37 Miyaji Y, Saika T, Yamamoto Y, Kusaka N, Arata R, Ebara S, Nasu Y, Tsushima T \& Kumon H. Effects of gonadotropin-releasing hormone agonists on bone metabolism markers and bone mineral density in patients with prostate cancer. Urology $2004 \mathbf{6 4}$ $128-131$.

38 Eriksson S, Eriksson A, Stege R \& Carlstrom K. Bone mineral density in patients with prostatic cancer treated with orchidectomy and with estrogens. Calcified Tissue International 1995 57 97-99.

39 Smith MR, Fallon MA, Lee H \& Finkelstein JS. Raloxifene to prevent gonadotropin-releasing hormone agonist-induced bone loss in men with prostate cancer: a randomized controlled trial. Journal of Clinical Endocrinology and Metabolism $2004 \mathbf{8 9}$ 3841-3846.

40 Ju HS, Leung S, Brown B, Stringer MA, Leigh S, Scherrer C, Shepard K, Jenkins D, Knudsen J \& Cannon R. Comparison of analytical performance and biological variability of three bone resorption assays. Clinical Chemistry $1997 \mathbf{4 3}$ 1570-1576.

41 Paoletti AM, Orru M, Lello S, Floris S, Ranuzzi F, Etzi R, Zedda P, Guerriero S, Fratta S, Sorge R, Mallarini G \& Melis GB. Short-term variations in bone remodeling markers of an oral contraception formulation containing $3 \mathrm{mg}$ of drospirenone plus 30 microg of ethinyl estradiol: observational study in young postadolescent women. Contraception 200470 293-298.

42 Grinspoon SK, Friedman AJ, Miller KK, Lippman J, Olson WH \& Warren MP. Effects of a triphasic combination oral contraceptive containing norgestimate/ethinyl estradiol on biochemical markers of bone metabolism in young women with osteopenia secondary to hypothalamic amenorrhea. Journal of Clinical Endocrinology and Metabolism 200388 3651-3656.

43 Nappi C, Di Spiezio Sardo A, Acunzo G, Bifulco G, Tommaselli GA, Guida M \& Di Carlo C. Effects of a low-dose and ultra-low-dose combined oral contraceptive use on bone turnover and bone mineral density in young fertile women: a prospective controlled randomized study. Contraception $200367355-359$.

44 Grinspoon S, Thomas L, Miller K, Herzog D \& Klibanski A. Effects of recombinant human IGF-I and oral contraceptive administration on bone density in anorexia nervosa. Journal of Clinical Endocrinology and Metabolism 200287 2883-2891.

45 Reed SD, Scholes D, LaCroix AZ, Ichikawa LE, Barlow WE \& Ott SM. Longitudinal changes in bone density in relation to oral contraceptive use. Contraception 200368 177-182.

46 Speroff L, Rowan J, Symons J, Genant H \& Wilborn W. The comparative effect on bone density, endometrium, and lipids of continuous hormones as replacement therapy (CHART study). A randomized controlled trial. JAMA $1996 \mathbf{2 7 6}$ 1397-1403.

47 Doren M, Nilsson JA \& Johnell O. Effects of specific post-menopausal hormone therapies on bone mineral density in post-menopausal women: a meta-analysis. Human Reproduction $2003 \mathbf{1 8}$ $1737-1746$.

Received 3 February 2005

Accepted 4 April 2005 